\title{
Vascular function in asthmatic children and adolescents
}

Leonardo Silva Augusto1, Grazielle Caroline Silva², José Felippe Pinho', Rosária Dias Aires², Virgínia Soares Lemos², Lidiana Fátima Correa Ramalho ${ }^{4}$, Nulma Souto Jentzsch ${ }^{3}$ and Maria Glória Rodrigues-Machado ${ }^{{ }^{*}}$

\begin{abstract}
Background: Epidemiological studies have demonstrated an increased incidence of cardiovascular events in patients with bronchial asthma, but little is known about the relationship between asthma and vascular function. The purpose of this study was to evaluate endothelial function and arterial stiffness in children and adolescents with asthma.
\end{abstract}

Methods: A cross-sectional controlled study was designed. Measurements of endothelial function and arterial stiffness in asthmatic (13.6 \pm 0.6 years) and control groups (14.9 \pm 0.7 years) were taken by the non-invasive peripheral arterial tonometry (EndoPAT2000) determined by using the natural logarithm of the reactive hyperemia index (LnRHI) and the augmentation index (Alx@75\%), respectively. Patients with asthma were also administered two questionnaires to evaluate asthma control and quality of life. Exercise functional capacity was evaluated using the Shuttle Walking Test (SWT). Only male participants were included in the present study.

Results: LnRHI and the walked distance during the SWT were similar between groups $(p=0.23$ and $p=0.50$, respectively). Alx@75\% was significantly higher in the asthmatic group (-7.75 \pm 1.7$)$ compared to the control group $(-15.25 \pm 1.8), p<0.04$. In the control group, the LnRHI correlated positively with baseline systolic blood pressure $(r=0.53, p=0.02)$ and mean arterial pressure $(r=0.50, p=0.03)$, age $(r=0.61, p=0.007)$, weight $(r=0.63, p=0.004)$ and height $(r=0.56, p=0.015)$. Besides that LnRHI correlated with FVC $(r=0.69, p=0.002), \mathrm{FEV}_{1},(r=0.53, p=0.03)$ and negatively with Tiffeneau index (FEV $/$ FVC\%, $r=-0.49 p=0.04)$. The LnRHI of the asthmatic group did not correlate with the different variables evaluated.

Conclusion: The increased Alx@75\% without changes in LnRHI in asthmatic patients could mean that an early detection of vascular impairment may precede endothelial dysfunction, and that different mechanisms may contribute to the pathogenesis and progression of cardiovascular events in this population. A large prospective and randomized controlled study should be done to evaluate the physiopathological mechanisms underlying the association between arterial stiffness and asthma.

Keywords: Endothelial dysfunction, Arterial stiffness, Reactive hyperemia index, Pulmonary function test, Exercise functional capacity, Quality of life

\footnotetext{
* Correspondence: maria.machado@cienciasmedicasmg.edu.br

${ }^{1}$ Faculdade Ciências Médicas-Minas Gerais, Pós-Graduação em Ciências da Saúde, 30130-110 Alameda Ezequiel Dias 275-Centro, Belo Horizonte, MG, Brazil

Full list of author information is available at the end of the article
} 


\section{Background}

Asthma is a chronic inflammatory disease with a high prevalence that affects different age groups, especially children [1]. The inflammation that occurs in asthma patients is not restricted to the lungs. There is also systemic inflammation, which is characterized by an increase in plasma of various pro-inflammatory cytokines, such as interleukin-6 (IL-6), tumor necrosis factor alpha (TNF- $\alpha$ ) and C-reactive protein (CRP) $[2,3]$.

Epidemiological studies have shown that asthma patients have a higher rate of cardiovascular diseases than patients without asthma [4-7]. Recent studies show an important association between the chronic systemic inflammation in asthma, and arterial stiffness, which is considered a prognostic factor and independent predictor of cardiovascular events $[8,9]$. In young adults and children with asthma, arterial stiffness is inversely correlated to the percentage of forced expiratory volume in the first second $\left(\mathrm{FEV}_{1} \%\right)[9,10]$, which demonstrating that correlation between pulmonary function and vascular stiffness is not limited to aging patients [11]. Moreover, it was observed that arterial stiffness tends to increase with asthma severity [8].

Endothelial dysfunction is currently considered to be the first event in a series of inflammatory or immune diseases, such as vasculitis and atherosclerosis [12]. This observation, coupled with the knowledge that asthma is considered an important inflammatory disease, led us to hypothesize that endothelial function could be changed in this population. Several studies have been recently performed in children and adolescents to assess endothelial function in different diseases [13, 14]. However, as far as we know, no previous study has evaluated the relationship between asthma and vascular dysfunction measuring simultaneously the reactive hyperemia index (RHI) and the augmentation index (Alx), noninvasive markers of endothelial function and arterial stiffness, respectively.

In the current study, we used EndoPAT2000 that quantifies the endothelium-mediated changes in vascular tone, elicited by a 5 -min occlusion of the brachial artery $[15,16]$. The increase in blood flow measured by the fingertip-mounted probe plethysmography that occurs when the cuff is deflated, stimulates the production and release of endothelium derived nitric oxide and cause vasodilation $[17,18]$. The dilation, manifested as reactive hyperemia, is captured by the EndoPAT2000 as an increase in the digital pulse volume amplitude, and the recordings are automatically analyzed by computerassisted analysis software [19]. Differently, AIx is widely used as an index of pulse wave reflection, and has been demonstrated to be an independent predictor of a cardiovascular event. This index modulates the central pressure profile [20], increasing aortic systolic pressure and decreasing aortic diastolic pressure [21]. Lower AIx reflects better arterial elasticity [18]. In healthy children and adolescents, EndoPAT2000 is feasible and has excellent reproducibility, providing an easy and reliable means of assessing endothelial function in this population [22].

\section{Material and methods}

Participants in the study were children and adolescents $(n=19)$ with a clinical and spirometric diagnosis of asthma, according to Global Strategy for asthma management and prevention [1]. The control group $(\mathrm{n}=18)$ was composed of healthy children and adolescents with anthropometric characteristics similar to the experimental group. Only male participants were included in the present study. All experimental protocols were approved by local ethics committee (protocol number \# 34878614.3.0000.5134, Comitê de Ética e Pesquisa da Faculdade Ciências Médicas - Minas Gerais - CEPCM-MG). All participants and parents or legal guardians signed the Informed Consent Form (ICF).

Endothelial dysfunction and arterial stiffness were assessed through peripheral arterial tonometry (PAT; EndoPAT2000, Itamar Medical, Caesarea, Israel), a noninvasive technology that captures a beat-to-beat plethysmographic recording of the fingers [15]. A pair of pneumatic sensors (plethysmographic probes) was placed on the index fingers of each hand. Baseline measurements were collected for $5 \mathrm{~min}$. After this time the blood pressure cuff, located on the subject's non-dominate arm, was inflated to $60 \mathrm{mmHg}$ above baseline systolic or at least $200 \mathrm{mmHg}$ of pressure for $5 \mathrm{~min}$ (occlusion period), confirmed by a reduction of the PAT tracing to zero. After the occlusion period, the cuff was quickly deflated to assess changes in digital pulse volumes, a consequence of reactive hyperemia, i.e., endothelium-dependent flow-mediated vasodilation. To calculate the RHI, the ratio of the results of the recovery (cuff deflated) and baseline periods for the test arm (A/ $\mathrm{B})$ was divided by the ratio of the results of the recovery and baseline periods for the control arm (C/D), and then multiplied by the baseline correction factor $[\mathrm{RHI}=(\mathrm{A} / \mathrm{B}) /$ $(\mathrm{C} / \mathrm{D}) \mathrm{x}$ baseline correction factor] (Additional file 1: Figure S3). According to the manufacturer's recommendation, values below 1.67 or 0.51 for the RHI or its natural logarithm of the reactive hyperemia index (LnRHI), respectively, characterize endothelial dysfunction [23]. These values are still not available in the literature for the pediatric population. The Alx was automatically calculated by the EndoPAT2000, using the pulse waveform at rest as a reference. The Alx was defined as the pressure difference between the peak of the reflection wave (P2) and the peak of the systolic wave (P1), expressed as a percentage of P1 $[\mathrm{AIx}=(\mathrm{P} 2-\mathrm{P} 1) / \mathrm{P} 1 \times 100]$. For the final analysis, the Alx was normalized to a heart rate of 75 beats per minute (Alx@75\%). LnRHI and Alx@75\% were calculated using an automatic algorithm of the EndoPAT2000 (Software 3.1.2). 
The assessment of asthma control and quality of life were performed using the Asthma Control QuestionaryACQ [24] and Pediatric Asthma Quality of Life Questionnaire-PAQLQ [25], respectively, both translated and culturally adapted to the Brazilian population [26, 27].

The assessment of functional capacity was performed using the Shuttle Walking Test (SWT) [28]. The test was stopped if a patient had unable to maintain the required speed or experienced dizziness, shortness of breath, or fatigue.

Variables were described as mean \pm SD. The unpaired $t$-test was used to compare the pulmonary function test parameters, LnRHI, Alx@75\% and SWT, between the groups. The Mann-Whitney test was used to compare the differences for non-parametric data between groups. The relationships between vascular dysfunction (LnRHI and Alx@75) and other variables (anthropometric data, pulmonary function test and cardiorespiratory variables) were done using Pearson correlation coefficient or Spearman when applied. Data analysis was performed with the software GraphPad Prism version 6.0. The significance level was set at $p<0.05$.

\section{Results}

Asthma control levels considered in this study were controlled $(\mathrm{n}=7)$, partly controlled $(n=7)$ and uncontrolled $(n=5)$. Asthmatic and control groups were similar in terms of age, weight, height, BMI, and walked distance, evaluated by SWT. The Tiffeneau index and $\mathrm{FEV}_{1}$ (\%) were significantly lower in the asthmatic group compared to the control group (Table 1). Six volunteers (31.57\%) from the asthmatic group had a positive bronchodilator test with at least a $12 \%$ increase in the $\mathrm{FEV}_{1}$ in accordance to GINA, 2015 [29].

Based on the domains of symptoms $(5.61 \pm 0.26)$, emotions (5.83 \pm 0.27$)$, activities $(5.32 \pm 0.30)$ and the general score $(5.59 \pm 0.25)$ assessed by PAQLQ, there was a moderate loss of quality of life in the asthmatic patients.

Figure 1 shows vascular function results. The LnRHI did not differ between the control and asthmatic groups $(p=0.23)$. However, the Alx@75\% was significantly higher in the asthmatic group $(p<0.001)$. In the control group, the LnRHI correlated positively with baseline systolic blood pressure $(r=0.53, p=0.02)$ and mean arterial pressure $(r=0.50, p=0.03)$, age $(r=0.61, p=0.007)$, weight $(r=0.63, p=0.004)$ and height $(r=0.56, p=0.015)$. Besides that LnRHI correlated with forced vital capacity (FVC, $r=0.69, p=0.002$ ), forced expiratory volume in the first second $\left(\mathrm{FEV}_{1}, r=0.53, p=0.03\right)$ and negatively with Tiffeneau index $\left(\mathrm{FEV}_{1} / \mathrm{FVC} \%, r=-0.49 p=0.04\right)$. The LnRHI of the asthmatic group did not correlate with the different variables evaluated. (Additional file 1: Table S1).
Table 1 Anthropometric data, pulmonary function test and walked distance evaluated by shuttle walking test

\begin{tabular}{|c|c|c|c|}
\hline Variables & Control & Asthmatic & $P$ value \\
\hline \multicolumn{4}{|l|}{ Anthropometric data } \\
\hline Age (years) & $14.89 \pm 0.68$ & $13.58 \pm 0.60$ & $p=0.15$ \\
\hline Weight (Kg) & $54.11 \pm 3.06$ & $51.79 \pm 3.02$ & $p=0.59$ \\
\hline Height (m) & $1.64 \pm 0.03$ & $1.63 \pm 0.03$ & $p=0.91$ \\
\hline $\mathrm{BMI}\left(\mathrm{Kg} / \mathrm{m}^{2}\right)$ & $19.86 \pm 0.73$ & $19.13 \pm 0.54$ & $p=0.42$ \\
\hline \multicolumn{4}{|l|}{ Pulmonary function test } \\
\hline $\mathrm{FVC}(\mathrm{L})$ & $3.85 \pm 0.24$ & $3.55 \pm .29$ & $p=0.46$ \\
\hline FVC (\% predicted) & $107.6 \pm 6.62$ & $93.2 \pm 5.23$ & $p=0.09$ \\
\hline $\mathrm{FEV}_{1}(\mathrm{~L})$ & $3.37 \pm 0.22$ & $2.78 \pm 0.27$ & $p=0.10$ \\
\hline $\mathrm{FEV}_{1}(\%$ predicted $)$ & $99.89 \pm 5.28$ & $82.69 \pm 6.24$ & $p=0.04$ \\
\hline $\mathrm{FEV}_{1} / \mathrm{FVC} \%$ & $87.89 \pm 1.72$ & $77.04 \pm 3.08$ & $p=0.005$ \\
\hline \multicolumn{4}{|l|}{ Hemodynamic data } \\
\hline $\mathrm{SAP}(\mathrm{mmHg})$ & $105.0 \pm 2.02$ & $100.9 \pm 2.64$ & $p=0.23$ \\
\hline $\mathrm{DAP}(\mathrm{mmHg})$ & $65.83 \pm 1.62$ & $62.11 \pm 1.96$ & $p=0.15$ \\
\hline $\mathrm{MAP}(\mathrm{mmHg})$ & $78.89 \pm 1.45$ & $75.75 \pm 2.05$ & $p=0.22$ \\
\hline $\mathrm{HR}(\mathrm{bpm})$ & $74 \pm 3$ & $80 \pm 2$ & $p=0.17$ \\
\hline \multicolumn{4}{|l|}{ Shuttle walking test } \\
\hline Walked distance(m) & $470.6 \pm 33.03$ & $442.4 \pm 25.37$ & $p=0.5$ \\
\hline
\end{tabular}

FVC forced vital capacity, $F E V_{1}$ forced expiratory volume in the first second, FEV $/$ /FVC Tiffeneau Index, SAP systolic arterial pressure, DAP diastolic arterial pressure, MAP mean arterial pressure, HR heart rate, SWT shuttle walking test

\section{Discussion}

As far as we know, no study has yet assessed the markers of endothelial function and arterial stiffness in asthmatic children and adolescents, using the EndoPAT2000. In this study we demonstrated that LnRHI did not differ between the control and asthmatic groups and the Alx@75\% was significantly higher in the asthmatic group, suggesting that the early detection of arterial stiffness marker may precede endothelial dysfunction.

Long-term exposure to inflammation, even at low levels, triggers a series of events that promote alterations in the regulation of lipid metabolism, atherosclerosis and endothelial dysfunction, which are precursors of cardiovascular disease [30, 31]. According to Tattersall et al. [32], asthmatic patients present higher rates of cardiovascular disease compared to participants without asthma, suggesting that there is a shared pathophysiological element between asthma and cardiovascular disease, triggering and perpetuating different types of comorbidities. In the present study, we investigated the association between the endothelial and pulmonary functions in children and adolescents with asthma. Only male participants were included in the present study. There is a higher probability of male children to develop early vascular changes compared to female children of the same age [33] and there are differences in the reactive hyperemia indexes when comparing male and female 

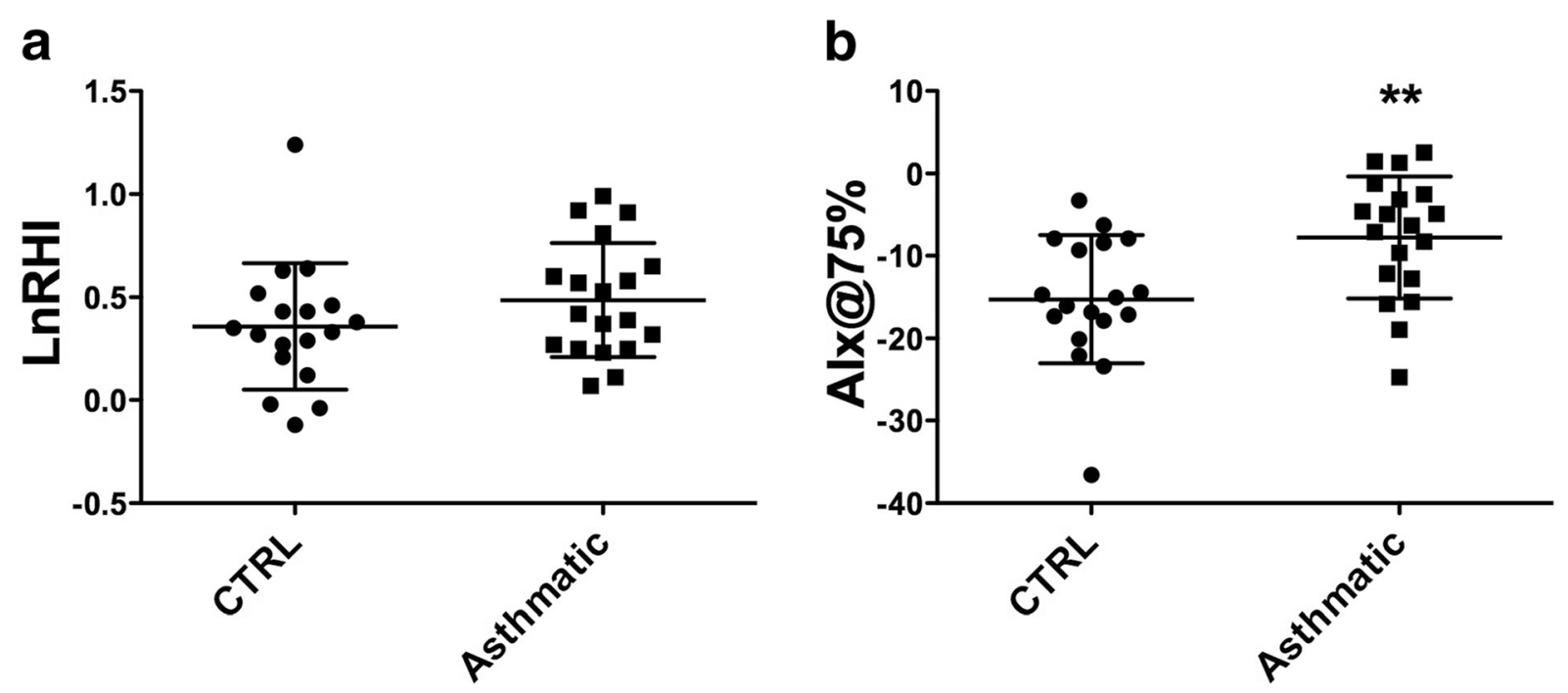

Fig. 1 Vascular function, given by the, natural logarithm of the reactive hyperemia index ( $L n R H I)$ and the augmentation index corrected for a heart rate of 75 bpm (Alx@75\%). ${ }^{* *} p<0.001$ compared to the control group

volunteers [33]. Moreover, females present hormonal fluctuations during the menstruation period and the first years of puberty, which can interfere with measurements. It is also difficult to control the use of contraceptives in adolescents, another important factor that contributed to the endothelium dysfunction. Also, only participants with a normal BMI were included in the present study because overweight and obesity are factors that lead to endothelial dysfunction [34].

In the current study, the LnRHI of the asthmatic group did not differ from control group. Similar results were observed by Moore et al. [35] through flow mediated dilation (FMD) technique, based on the same physiological mechanism of PAT [15]. A main advantage of the EndoPAT2000 system on FMD is that the contralateral arm serves as an internal control of measurement [36] and this technique is operator-independent [36]. In addition, EndoPAT2000 enables the simultaneous measurement of endothelial function and arterial stiffness. In the current study, LnRHI of control group correlated positively with baseline systolic blood pressure and mean arterial pressure, anthropometric data (age, weight, height), and pulmonar function test parameters (FVC, $\mathrm{FEV}_{1}$ ). In addition, in control group the LnRHI correlated negatively with Tiffeneau index. A large sample sized, prospective and randomized controlled study should be addressed to evaluate the value of these associations.

According to Harkness et al. [37] asthma is not only an airway disease, but a vascular disease due to an expansion and morphological dysregulation of the bronchial vascular network in the airways of asthmatics, such as an increased number, size and density of blood vessels, as well as vascular leakage and plasma engorgement. Recently we demonstrated $[38,39]$ in a model of chronic asthma induced by ovalbumin (OVA) that asthmatic mice exhibited an increase in size and number of vessels within the airway wall, contributing to thickening of the wall. OVA mice also presented a significant increase in myocyte diameter of the right ventricle, suggesting that structural remodeling led to an increase in pulmonary vascular resistance and subsequent right ventricular hypertrophy. However, the pathophysiological impact of the increased vasculature in the bronchial wall and its significance to pulmonary function in asthma [37] and systemic circulation is unrecognized at this time.

Accumulating data have shown an important association between chronic systemic inflammation in asthma and arterial stiffness [9-11], which is considered a prognostic factor and an independent predictor of cardiovascular events [8]. In the present study, the Alx@75\% was significantly higher in the asthmatic group but different from other authors [8-10], there was no correlation between this index and the pulmonary function parameters and reversibility of airway obstruction in the asthmatic group. This suggests that, besides airway obstruction, there are other factors contributing to the higher incidence of cardiovascular outcomes in this population. The results of Moore et al. [35] corroborates with this line of thought. Moore et al. [35] compared the arterial stiffness in asthmatic adults (18 to 45 years), having controlled and partially controlled asthma, with healthy volunteers, which were matched for age, body mass index, level of physical activity, and maximum oxygen consumption $\left(\mathrm{VO}_{2} \max \right)$. These authors observed that arterial stiffness was significantly higher in patients with 
asthma, suggesting that structural changes in arterial vessels are related to pulmonary disease and are not a consequence of reduced physical activity or $\mathrm{VO}_{2} \mathrm{max}$. Similarly to Moore et al. [35] results, in the present study healthy volunteers were matched for age, high, body mass index, and exercise functional capacity.

Despite the exclusion of factors that could mislead the identification of endothelial dysfunction, such as female gender, changes in the BMI, smoking and diseases that can compromise endothelial function such as diabetes, this study has some limitations. The first limitation is the lack of knowledge about the lipid profile of the participants. Inflammatory and hemostatic abnormalities present in children with familiar hypercholesterolemia contribute to endothelial dysfunction [40]. Another limitation of this study was the lack of assessment of the pubertal stage of the participants. Endothelial function increases during puberty. Children at advanced stages of pubertal development, assessed by the scale of Tanner, have a greater peripheral vasodilator response measured by PAT [41]. Lastly, black volunteers were not excluded from the study. This ethnicity is usually associated with impaired vascular function compared to whites, due to the lower bioactivity of nitric oxide in the microcirculation of the forearm, which is associated with a reduced vasodilator response of the smooth muscle in response to nitric oxide donors [42].

In conclusion, this study demonstrated that LnRHI did not differ between the groups and the Alx@75\% was significantly higher in the asthmatic group. The increase in Alx@75\% in asthmatic patients, with no changes in LnRHI, may indicate that early detection of vascular dysfunction may precede endothelial dysfunction and that different mechanisms may contribute to the pathogenesis and progression of cardiovascular events in this population.

\section{Additional file}

Additional file 1: Supplemental material. (DOCX 1048 kb)

\section{Abbreviations}

ACQ: Asthma control questionnaire; Alx@75\%: Alx normalized to a heart rate of 75 beats per minute; Alx: Augmentation index; BMl: Body mass index; BP: Blood pressure; CRP: C-reactive protein; $\mathrm{FEV}_{1}$ : Forced expiratory volume in the first second; FVC: Forced vital capacity; HR: Heart rate; IL-6: Interleukin-6; $\mathrm{LnRHI}$ : Natural logarithm of the reactive hyperemia index (LnRHI); MAP: Mean arterial pressure; PAQLQ: Pediatric asthma quality of life questionnaire; $\mathrm{RHI}$ : Reactive hyperemia index; RR: Respiratory rate; SWT: Shuttle walking test; TNF-a: Tumor necrosis factor alpha

\section{Acknowledgements}

This work was supported by the Fundação Lucas Machado (FELUMA), Faculdade Ciências Médicas-Minas Gerais, Pós Graduação em Ciências da Saúde. Pinho JF received support from the Coordenação de Aperfeiçoamento de Pessoal de Nível Superior-CAPES/Brazil. Bárbara Fernandes Pinto and Lucas Carvalho de Oliveira Moisés, undergraduate students, helped with data collection and Bárbara Fernandes Pinto received support from Fundação de Amparo à Pesquisa do Estado de Minas Gerais (FAPEMIG.), Brazil. We are thankful to Isabel Cristina Gomes for additional statistical assistance.

\section{Funding}

This study was supported by the Fundação de Apoio a Pesquisa do Estado de Minas Gerais (FAPEMIG), and Programa Nacional de Pós-doutorado (PNPD) from Coordenação de Aperfeiçoamento de Pessoal de Nível Superior (CAPES).

\section{Availability of data and materials}

All data and materials will be available for access upon request to the corresponding author in the email: maria.machado@cienciasmedicasmg.edu.br.

\section{Authors' contributions}

LSA conceived the study, performed the experiments, analyzed, and interpreted the data, performed statistical analyses, wrote and edited the manuscript; GCS, RDA and JFP performed the experiments, analyzed and interpreted the data, and edited the manuscript; VSL interpreted the data, wrote and edited the manuscript; NSJ and LFCR selected patients and performed the experiments; MGRM conceived the study, designed and analyzed and interpreted the data, drafted, edited the manuscript. All authors read and approved the final manuscript.

\section{Competing interests}

The authors declare that they have no competing interests.

\section{Consent for publication}

Not applicable.

\section{Ethics approval and consent to participate}

All experimental protocols were approved by local ethics committee Comitê de Ética e Pesquisa da Faculdade Ciências Médicas de Minas Gerais (protocol number \# 34878614.3.0000.5134, CEPCM-MG). All participants and parents or legal guardians signed the Informed Consent Form (ICF).

\section{Author details}

${ }^{1}$ Faculdade Ciências Médicas-Minas Gerais, Pós-Graduação em Ciências da Saúde, 30130-110 Alameda Ezequiel Dias 275-Centro, Belo Horizonte, MG, Brazil. ${ }^{2}$ Departamento de Fisiologia e Biofísica da Universidade Federal de Minas Gerais, Belo Horizonte, MG, Brazil. ${ }^{3}$ Departamento de Medicina, Faculdade Ciências Médicas-Minas Gerais, Belo Horizonte, MG, Brazil.

${ }^{4}$ Unidade de Referência de Saúde Saudade, Prefeitura de Belo Horizonte (URS Saudade- SUS BH), Belo Horizonte, MG, Brazil.

Received: 23 March 2016 Accepted: 10 December 2016

Published online: 17 January 2017

\section{References}

1. FitzGerald JM, Bateman ED, Boulet LF, Cruz AA, Haahtela T, Levy ML, O'Byrne P, Paggiaro P, Pedersen SE, Soto-Quiroz M, et al. Global strategy for asthma management and prevention. 2015.

2. Wood LG, Baines KJ, Fu JJ, Scott HA, Gibson PG. The neutrophilic inflammatory phenotype is associated with systemic inflammation in asthma. Chest. 2012;142(1):86-93.

3. Girdhar A, Kumar V, Singh A, Menon B, Vijayan VK. Systemic inflammation and its response to treatment in patients with asthma. Respir Care. 2011;56(6):800-5.

4. Iribarren C, Tolstykh IV, Miller MK, Sobel E, Eisner MD. Adult asthma and risk of coronary heart disease, cerebrovascular disease, and heart failure: a prospective study of 2 matched cohorts. Am J Epidemiol. 2012;176(11):1014-24.

5. Schroeder EB, Welch VL, Couper D, Nieto FJ, Liao DP, Rosamond WD, Heiss G. Lung function and incident coronary heart disease - The atherosclerosis risk in communities study. Am J Epidemiol. 2003;158(12):1171-81.

6. Schanen JG, Iribarren C, Shahar E, Punjabi NM, Rich SS, Sorlie PD, Folsom AR. Asthma and incident cardiovascular disease: the atherosclerosis risk in communities study. Thorax. 2005;60(8):633-8.

7. Onufrak S, Abramson J, Vaccarino V. Adult-onset asthma is associated with increased carotid atherosclerosis among women in the atherosclerosis risk in communities (ARIC) study. Atherosclerosis. 2007;195(1):129-37.

8. Nurnberger J, Keflioglu-Scheiber A, Saez AMO, Wenzel RR, Philipp T, Schafers RF. Augmentation index is associated with cardiovascular risk. J Hypertens. 2002;20(12):2407-14.

9. Sun WX, Jin D, Li Y, Wang RT. Increased arterial stiffness in stable and severe asthma. Respir Med. 2014;108(1):57-62. 
10. Weiler Z, Zeldin Y, Magen E, Zamir D, Kidon MI. Pulmonary function correlates with arterial stiffness in asthmatic patients. Respir Med. 2010;104(2):197-203.

11. Ayer JG, Belousova EG, Harmer JA, Toelle B, Celermajer DS, Marks GB. Lung function is associated with arterial stiffness in children. Plos One. 2011;6(10):e26303.

12. Libby $P$, Okamoto $Y$, Rocha VZ, Folco E. Inflammation in atherosclerosis: transition from theory to practice. Circ J. 2010;74(2):213-20.

13. Koska J, Schwartz EA, Mullin MP, Schwenke DC, Reaven PD. Improvement of postprandial endothelial function after a single dose of Exenatide in individuals with impaired glucose tolerance and recent-onset type 2 diabetes. Diabetes Care. 2010;33(5):1028-30.

14. Kelly AS, Metzig AM, Steinberger J, Braunlin EA. Endothelial function in children and adolescents with mucopolysaccharidosis. J Inherit Metab Dis 2013:36(2):221-5.

15. Kuvin JT, Patel AR, Sliney KA, Pandian NG, Sheffy J, Schnall RP, Karas RH, Udelson JE. Assessment of peripheral vascular endothelial function with finger arterial pulse wave amplitude. Am Heart J. 2003;146(1):168-74.

16. Ruan Y, Wei W, Yan J, Sun L, Lian H, Zhao X, Liang R, Xiaole L, Fan Z. Time rate of blood pressure variation is associated with endothelial function in patients with metabolic syndrome. Int Heart J. 2016;57(2):226-33.

17. Nohria A, Gerhard-Herman M, Creager MA, Hurley S, Mitra D, Ganz P. Role of nitric oxide in the regulation of digital pulse volume amplitude in humans. J Appl Physiol (1985). 2006;101(2):545-8.

18. Hedetoft M, Olsen NV. Evaluation of endothelial function by periphera arterial tonometry and relation with the nitric oxide pathway. Nitric Oxide. 2014:42:1-8

19. Higashi Y. Assessment of endothelial function. History, methodological aspects, and clinical perspectives. Int Heart J. 2015;56(2):125-34.

20. Jeroncic A, Gunjaca G, Mrsic DB, Mudnic I, Brizic I, Polasek O, Boban M. Normative equations for central augmentation index: assessment of inter-population applicability and how it could be improved. Sci Rep. 2016;6:27016.

21. Nelson MR, Stepanek J, Cevette M, Covalciuc M, Hurst RT, Tajik AJ. Noninvasive measurement of central vascular pressures with arterial tonometry: clinical revival of the pulse pressure waveform? Mayo Clin Proc. 2010;85(5):460-72.

22. Selamet Tierney ES, Newburger JW, Gauvreau K, Geva J, Coogan E, Colan SD, de Ferranti SD. Endothelial pulse amplitude testing: feasibility and reproducibility in adolescents. J Pediatr. 2009:154(6):901-5.

23. Bruno RM, Gori T, Ghiadoni L. Endothelial function testing and cardiovascular disease: focus on peripheral arterial tonometry. Vasc Health Risk Manag. 2014;10:577-84.

24. Juniper EF, O'Byrne PM, Guyatt GH, Ferrie PJ, King DR. Development and validation of a questionnaire to measure asthma control. Eur Respir J. 1999;14(4):902-7.

25. Juniper EF. How important is quality of life in pediatric asthma? Pediatr Pulmonol Suppl. 1997;15:17-21.

26. Roxo JPF, Ponte EV, Ramos DCB, Pimentel L, D'Oliveira Júnior A, Cruz AA Portuguese-language version of the Asthma Control Test: validation for use in Brazil. J Bras Pneumol. 2010;36:159-66.

27. La Scala CSK, Naspitz CK, Solé D. Adaptation and validation of the Pediatric Asthma Quality of Life Questionnaire (PAQLQ) in Brazilian asthmatic children and adolescents. J Pediatr. 2005;81:54-60.

28. Singh SJ, Morgan MDL, Scott S, Walters D, Hardman AE. Development of a shuttle walking test of disability in patients with chronic airways obstruction. Thorax. 1992:47(12):1019-24.

29. GINA. Global strategy for asthma management and prevention. 2015.

30. Hadi HA, Carr CS, Al Suwaidi J. Endothelial dysfunction: cardiovascular risk factors, therapy, and outcome. Vasc Health Risk Manag. 2005;1 (3):183-98.

31. Tousoulis D, Charakida M, Stefanadis C. Endothelial function and inflammation in coronary artery disease. Heart. 2006;92(4):441-4.

32. Tattersall MC, Guo M, Korcarz CE, Gepner AD, Kaufman JD, Liu KJ, Barr RG, Donohue KM, McClelland RL, Delaney JA, et al. Asthma predicts cardiovascular disease events: the multi-ethnic study of atherosclerosis. Arterioscler Thromb Vasc Biol. 2015;35(6):1520-5.

33. Chen Y, Dangardt F, Osika W, Berggren K, Gronowitz E, Friberg P. Age- and sex-related differences in vascular function and vascular response to mental stress. Longitudinal and cross-sectional studies in a cohort of healthy children and adolescents. Atherosclerosis. 2012:220(1):269-74.
34. Pareyn A, Allegaert K, Verhamme P, Vinckx J, Casteels K. Impaired endothelial function in adolescents with overweight or obesity measured by peripheral artery tonometry. Pediatr Diabetes. 2015;16(2):98-103.

35. Moore LE, Bhutani M, Petersen SR, McMurtry MS, Byers BW, Tedjasaputra V, Stickland MK. Physical activity, fitness, and vascular health in patients with asthma. J Allergy Clin Immunol. 2015;136(3):809-11.

36. Arrebola-Moreno AL, Laclaustra M, Kaski JC. Noninvasive assessment of endothelial function in clinical practice. Rev Esp Cardiol (Engl Ed). 2012;65(1):80-90.

37. Harkness LM, Ashton AW, Burgess JK. Asthma is not only an airway disease, but also a vascular disease. Pharmacol Ther. 2015;148:17-33.

38. Rodrigues-Machado MG, Magalhaes GS, Cardoso JA, Kangussu LM, Murari A, Caliari MV, Oliveira ML, Cara DC, Noviello ML, Marques FD, et al. AVE 0991, a non-peptide mimic of angiotensin-(1-7) effects, attenuates pulmonary remodelling in a model of chronic asthma. Br J Pharmacol. 2013;170(4):835-46.

39. Magalhaes GS, Rodrigues-Machado MG, Motta-Santos D, Silva AR, Caliari MV, Prata LO, Abreu SC, Rocco PR, Barcelos LS, Santos RA, et al. Angiotensin-(1-7) attenuates airway remodelling and hyperresponsiveness in a model of chronic allergic lung inflammation. Br J Pharmacol. 2015;172(9):2330-42.

40. Charakida M, Masi S, Loukogeorgakis SP, Deanfield JE. The role of flow-mediated dilatation in the evaluation and development of antiatherosclerotic drugs. Curr Opin Lipidol. 2009:20(6):460-6.

41. Bhangoo A, Sinha S, Rosenbaum M, Shelov S, Ten S. Endothelial function as measured by peripheral arterial tonometry increases during pubertal advancement. Hormone Res Paediatrics. 2011;76(4):226-33.

42. Morris AA, Patel RS, Binongo JNG, Poole J, al Mheid I, Ahmed Y, Stoyanova N, Vaccarino V, Din-Dzietham R, Gibbons GH, et al. Racial differences in arterial stiffness and microcirculatory function between black and white Americans. Im Heart Assoc. 2013;2(2):e002154

\section{Submit your next manuscript to BioMed Central and we will help you at every step:}

- We accept pre-submission inquiries

- Our selector tool helps you to find the most relevant journal

- We provide round the clock customer support

- Convenient online submission

- Thorough peer review

- Inclusion in PubMed and all major indexing services

- Maximum visibility for your research

Submit your manuscript at www.biomedcentral.com/submit
) Biomed Central 